\title{
S-LCA applications: a case studies analysis
}

\author{
Maria C. Lucchetti ${ }^{1}$, Gabriella Arcese ${ }^{1}$, Marzia Traverso ${ }^{2, *}$, and Chiara Montauti ${ }^{1}$ \\ ${ }^{1}$ Roma Tre University, Via Silvio d'Amico 77, Rome, 00145, Italy \\ ${ }^{2}$ RWTH Aachen University, Mies-van-der-Rohe-Straße 1, Aachen, 52074, Germany
}

\begin{abstract}
S-LCA is defined by the guidelines established by the 2009 UNEP/SETAC, as "a technique for assessing social (real or potential) impacts with the aim of evaluating the socio-economic aspects of the products and their potential impacts, positive and negative, along their life cycle, including the extraction and processing of raw materials, production, distribution, use, reuse, maintenance, recycling and final disposal"[1]. In addition, the S-LCA follows the same structure presented in the ISO 14040-14044 (2006) standards for the Life cycle assessment method[2][3]. The number of case studies that emerge from the literature show that this tool is a significant success among the scientific community and industrial sector. Based on a systematic review of the literature conducted on the case studies reported in the literature between 2013-2017 based on 48 case studies, we have been carried out and mapped some productive sectors such as the agri-food sector, automotive, metal and textile. This analysis has made it possible to highlight how, especially in the last 2 years, the application to the practical cases of the S-LCA methodology has been increased, as well as the number of integrated use of the two environmental LCA and S-LCA instruments, allowing so the application also to SMEs.
\end{abstract}

\section{Introduction}

The Social Life Cycle Assessment (S-LCA) is a methodology defined by the UNEP/SETAC for evaluating the social impacts (actual or potential), positive or negative, which concern stakeholders over the whole life cycle [1]. These impacts concern the effects generated on the involved stakeholders, or rather the end-point social indicators like wellness, health and human dignity [6].

The S-LCA is a tool, which necessitates an improved development, because today, it presents still significant weakness. Nevertheless, it is clear that, this tool is more and more widespread, because it has increased the interest of the reference scientific community. During the last years the scientific outputs have increased, above all from the publication of UNEP/SETAC and Methodological Sheets guidelines. These Guidelines, published in 2009, identify five categories of stakeholders (workers, consumers, value chain actors, local community, society) and define the social impacts as result of positive or negative pressure on the endpoints [1]. Then, in 2013, the Methodological Sheets were published by

\footnotetext{
*Corresponding author: marzia.traverso@inab.rwth-aachen.de
} 
UNEP/SETAC for the subcategories providing a guide in order to simplify the most difficult data-gathering in the realization of S-LCA, which were updated in 2013 [4].

Given the increase of papers about case studies and practical application of S-LCA, this work is intended to investigate the main reasons and interests, which have given a boost to this increase. For this reason, it is choosing to conduct an analysis of the literature focused on case studies to analyze how and in which sectors the S-LCA methodology is applied.

First of all, it has been carried out a research about the S-LCA, taking 2013/2017 as the reference period, through the using of the keywords "Social life cycle assessment" "SLCA" "Social LCA". Then, the papers, which indicate the practical applications of above methodology, have been selected, by ensuring that, from 235 works initially showed, a sample of 48 works has been selected. The aim of this work is that to define the development of different applications and case studies, which are mainly focused on the products, application methods of S-LCA and on the categories and subcategories of interested parties, which were examined, in order to provide a classification on the wide variety of contributions with regard to S-LCA. At second it was done a review, following qualitative approach, jointly using the automated analysis of text and the analysis of lexicon to identify some keywords, which has enabled us to outline a map of the current situation about S-LCA.

\section{Methods}

As is known, the S-LCA has not a reference standard, which reports in detail an appropriate procedure to carry out an analysis of social impacts associated to a product or to a service. In this way, also given the great success received over the time by this tool, different approaches have developed, each of which aims to define a reference theoretical basis, trying to reduce the great flexibility provided for by the Guidelines [7].

In fact, as already stated in the literature, in the majority of works, typical methods and approaches of other contexts and disciplines are used, producing the distortive effect of not defining a clear and useful path for a setting standard, which enables the establishment of a unique method, universally accepted by the scientific community [8]. The analysis carried out for a systematic literature review conducted by the authors consists in a preliminary investigation into case studies about the S-LCA between 2009 and 2015. From this study it was selected a total of 24 works, which prefer a full approach of the S-LCA, exemption from the initial selection some papers, which present a too clean cut and the ones that are focused on strictly particular aspects [7].

The S-LCA methodology reproduces the same stages used for the Life Cycle Assessment (LCA), in order to understand the social impacts, real or potential, connected to life cycle of a product or a service. Thanks to the S-LCA it is possible to improve the socioeconomic conditions of stakeholder, which are connected, directly or indirectly, to the life cycle product. From preliminary analysis, as seen in Fig. 1, it emerged that, the main topic, which contains more than half of works about S-LCA, concerns the "Environmental Science", followed by "Engineering" and by "Energy", while only little more than $15 \%$ of scientific publication fall under social science area and approximately $10 \%$ of them fall under business e management. With reference to stakeholder categories, which are useful for the definition of categories and impact subcategories for the analysis of social aspects, those which are commonly used in the case studies are: "worker", "society" and "local community", while the other categories "consumer" and "value actor chain" tend to be under-utilized. In addition, as can be seen in the Fig.2, also the using of the "other stakeholder categories" appear to have increased between 2013 and 2017. 


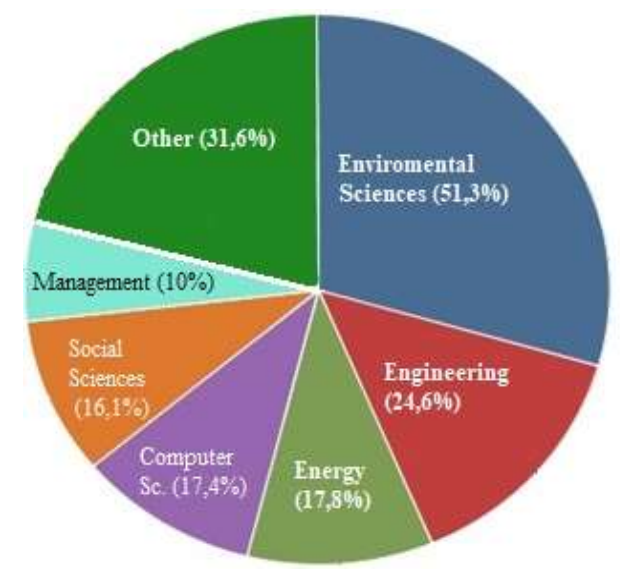

Fig. 1. Percentage of documents by subject area [9].

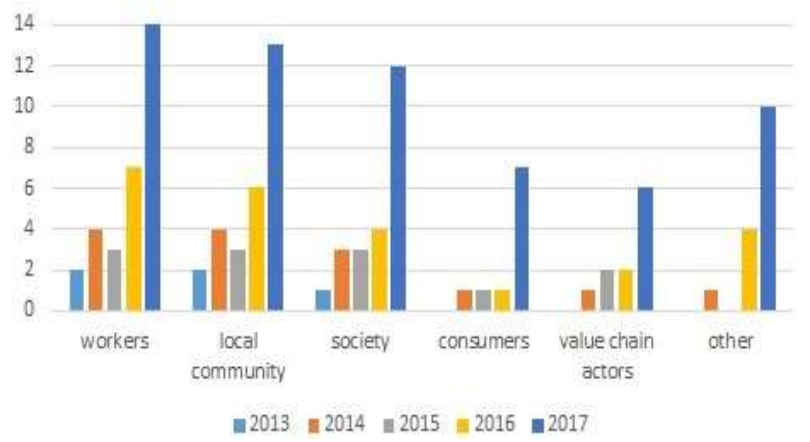

Fig. 2. Growth of stakeholder categories (personal elaboration of the authors).

\section{Results and discussion}

\subsection{Results on methodology}

With reference to stakeholder categories, which are useful for the definition of categories and impact subcategories for the analysis of social aspects, those which are commonly used in the case studies are: worker, society and local community, while the other categories consumer and value actor chain still tend to be under-utilized.

As is known, UNEP/SETAC guidelines provide for including other stakeholder categories to the principal five already expected, for the identification of more detailed and specific subcategories [1,4]. In a lot of works, in fact, further stakeholder categories are added, in order to detect more specific and detailed economic, environmental and social aspects for the studies carried out [10].

As regards the analysed impact subcategories, in 2013 these mainly concerned "wage", "working hours" and "community engagement", but with the increase of case studies publishing, more and more subcategories had been taken into account, concerning relevant social affairs and in line with the united nations human rights, like child labor, forced labor, freedom of association, gender bias, education and so on. In the Fig.3 it is shown the increasing of the number of impact categories and social issues, which are considered in the case studies in the range examined. 


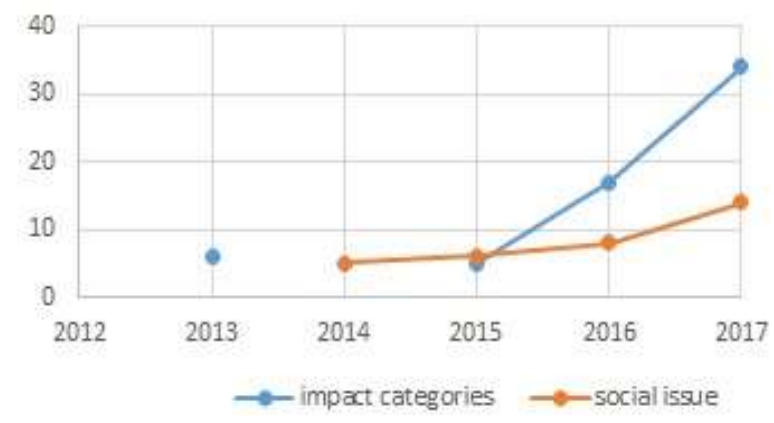

Fig. 3. Number of impact categories between 2013 and 2017 (personal elaboration of the authors).

Social aspects with different implications can come from each application and case study: positive and negative impacts, resulting from the output of a good, can arise. For this reason, the S-LCA is considered as a tool for supporting companies and institutions which aim to improve social performance and conditions of any stakeholder concerned $[11,12]$.

For evaluating some social aspects related to the life-cyle of a product, all or only some phases of production, in relation to the specificity level of carried out analysis, could be considered. The S-LCA is also used to compare social impacts, which arise from the production of a good in a certain territory, where there is the same good import from abroad [13]. A further aspect, as result of the joint use of LCA and the S-LCA, concerns the crucial role of results, which are obtained through this approach, for the processes of decision making: for example, it is possible to evaluate social and environmental effects caused by the introduction of a certain innovation in a company production system, comparing two different scenarios characterized by the introduction or not of innovation [14].

\subsection{Results on case studies and applications}

Many times the S-LCA analysis could be carried out following two different phases: a general evaluation trough a top-down approach, that is more a risk assessment. It can be done for example thanks to the "Social Hotspot Database" (SHDB) using to examine potential social problems of a certain stakeholder category, and a more specific evaluation trough a bottom-up approach, mainly used for a detailed data collection [15]. These models concern both the wording of hybrid models that integrate the S-LCA with input/output analysis [16] and the multi-criteria decision methodology (MCDM) [15].

For evaluating social impacts, many times, the government is selected as "multidimensional stakeholder" given its non-regulatory role, but it can also cater for the production of some good or services and be so affected by the product itself. In this regard, in the Guidelines, the government "is not proposed as a separate category for the interested parties in this context, because the good production impact on governments, is not a dimension which was put forward in the facility and in the literature about Corporate social responsability [...] however, because of the goal and the definition of the scope, it may be necessary specifically face this stakeholder" [1].

So the role of the state is crucial and fundamental, because it appears across the S-LCA analysis. In 2015, an example is given by the work of Papong, whose aim is to realize a "social inventory" trough a wording of input/output model, by selecting six of the main social questions of interest: employment, number of employees, working time, remuneration, event of accident and workplace deaths [17]. In the table 1 it appears that S- 
LCA field application concerns all sectors of production. The main sectors of production, in which this tool is used other different and multiple from the agri-food sector to construction, chemical-pharmaceuticals, cosmetics, health, energetic, technological, textile, automotive sectors and to wood productive systems.

Table 1. Sector and product investigated.

\begin{tabular}{|c|c|c|}
\hline \multicolumn{3}{|c|}{ Case Studies and applications } \\
\hline & Sector & Product \\
\hline 1 & Agri-food sector & $\begin{array}{l}\text { Dairy Farm, Citrus, Sugarcane, } \\
\text { Tomato }\end{array}$ \\
\hline 2 & Building sector & $\begin{array}{l}\text { Raw Material Supply } \\
\text { Chain/Capacitor, Retrofitting Of A } \\
\text { House }\end{array}$ \\
\hline 3 & $\begin{array}{l}\text { Chemical and biochemical } \\
\text { products }\end{array}$ & $\begin{array}{l}\text { Mineral fertilizers and industrial } \\
\text { compost, polyethylene production, } \\
\text { bioethanol production, } \\
\text { fossil fuels and biofuels }\end{array}$ \\
\hline 4 & Cosmetic and sanitary Sector & Cocoa Soap, Sanitary Pads \\
\hline 5 & Energy & $\begin{array}{l}\text { Solar Power Plant, Energy Supply in } \\
\text { Production }\end{array}$ \\
\hline 6 & Technologies & $\begin{array}{l}\text { Materials For Battery, Integrated } \\
\text { Circuit, Electronic ICT Waste }\end{array}$ \\
\hline 7 & Steel Sector & Steel product \\
\hline 8 & Textile Sector & T-shirt, jeans \\
\hline 9 & $\begin{array}{c}\text { Wood-Based Production } \\
\text { System }\end{array}$ & $\begin{array}{l}\text { Wood-Based Product, Bamboo } \\
\text { Bicycle Frames }\end{array}$ \\
\hline 10 & Other (i.e. Automotive) & \\
\hline
\end{tabular}

As it is shown in the Table 1, the majority S-LCA applications above all concern the agri-food sector, which deepens and examines the different social aspects and the numerous problems, that characterizes this field. The S-LCA applied to productive field has allowed to analyze the social benefits, which concern different types of crops grown. [11], and also to evaluate the social aspect linked to life-cycle of a specific food [18]. In some cases, this analysis did not allow to outline a major difference between social benefits [18], while in the other studies, there was evidence of positive social effects on the society and on the other actors in the value chain, recording positive impacts for the local community and for the employees, while the main negative impacts concern the health and the security [19].

The possibility to provide useful guidance for formulating solution and improvement of social aspects for the policy makers is a further and relevant aspect, that come from the analysis of results S-LCA applications. In this regard, we could consider productive sectors, which are particularly relevant for the territorial development and present social issues, for example in Italy the immigrant workers in the agri-food sector [10]. The results, that arise from these types of case studies, allow to evaluate the social performance of different cases, providing a valuable contribution in support of entrepreneurs and policy makers, who project and implement regional planning strategies. With reference to the analysis about 
food and drink sector, the main problems, linked to the evaluation of social impacts above all in relation to small and medium-sized enterprises (SME), have arisen. The methodology proposed focuses on work conditions along the supply chain of SPE products. The key stakeholders for this type of analysis are limited to only employees and local communities affected by this production process, with the primary aim of contributing to realize an easier methodology to apply to SPE of the sector, ensuring to the consumer a greater transparency along the supply chain of product, for facilitating the implementation and the promotion of public and standard sectoral policies [20].

\section{Conclusion}

The purpose of this work has been to try to define the state of the art related to S-LCA practical application. The review of case studies has shown how during the past few years, the number of S-LCA applications is particularly increased. The growth of the number of this kind of work in in terms of scientific research, shows that the growing popularity of this tool is not only spread between scholars and researchers, but also between those who are members of reference scientific community, for example companies and policy makers, because the awareness about the S-LCA magnitude of the results ins increased. It is reasonable to assume the this widely dissemination can be particularly attributed to the Guidelines and Methodological Sheets, which provide useful indications for the application and the using of S-LCA.

However, among the main problems that are found in the assessment of social aspects, there is above all the lack of a general framework of reference that gives the possibility to those who intend to make these assessments, to be able to proceed in a univocal and more objective way to analysis of social problems. This aspect still requires updates and improvements, as to date there is still a high degree of uncertainty and above all of difficulties with regard to the retrieval of data, the complexity in defining the functional unit of reference and the boundaries of the system and the absence of collaboration of certain categories of stakeholders. The analysis made it possible to highlight that the SLCA is increasingly being used together with the other impacts lifecycle assessment techniques: LCA and LCC. Above all in the case of the LCSA, it is possible to evaluate in a comprehensive way the sustainability linked to the life cycle of products and / or services and to be able to make comparisons and useful choices both within the corporate assessments and for more purely political and social decisions compared to the subject performing the analysis. Finally, it has been noted that the S-LCA diffusion involves numerous productive sectors, first of all the agri-food sector, for which the highest number of case studies are published.

\section{References}

1. UNEP/SETAC, UNEP/SETAC Life-Cycle Initiative Guidelines for social life cycle assessment of products (United Nation Environment Programme, Paris, 2009).

2. ISO - International Organization for Standardization, ISO 14040: Environmental management - Life cycle assessment - Principles and framework (ISO copyright office, Geneva, 2006).

3. ISO - International Organization for Standardization. ISO 14044: Environmental management - Life cycle assessment - (2006)

4. UNEP/SETAC. Methodological sheets of sub-categories of impact for a Social LCA. Available online at http://lcinitiative.unep.fr. (2013). 
https://www.lifecycleinitiative.org/wp-content/uploads/2013/11/S-

LCA_methodological_sheets_11.11.13.pdf

5. C. Benoît, G.A. Norris, S. Valdivia, A. Ciroth, A. Moberg, U. Bos, S. Prakash, C. Ugaya, T. Beck, Int. J. LCA 15, 2 (2010)

6. R. Wu, D. Yang, J. Smith, Sust. 6, 7, 4200-4226 (2014)

7. G. Arcese, M.C. Lucchetti, I. Massa, C. Valente, Int. J. LCA 23, 394-405 (2016).

8. J. Martínez-Blanco, A. Lehmann, P. Muñoz, A. Antón, M. Traverso, J. Rieradevall, M. Finkbeiner, J. Clean. Prod. 69, 34-48 (2014)

9. SCOPUS https://www.scopus.com/home.uri

10. A.I. De Luca, N. Iofrida., A. Strano, G. Falcone, G. Gulisano, Integr. Envir. Assess. and Manang. 11, 383-396 (2014)

11. J.F. Hake, J.C. Koj, W. Kuckshinrichs, H. Schlör, A. Schreiber, C. Wulf, P. Zapp, T. Ketelaer, Energy Procedia 105, 3403-3410 (2017)

12. M.K. Musaazi, A.R. Mechtenberg, J. Nakibuule, R. Sensenig, E. Miyingo, J.V. Makanda, A. Hakimian, M.J. Eckelman, J. Clean. Prod. 96, 569-579 (2013)

13. N. Tecco, C. Baudino, V. Girgenti, C. Peano, Science of the Total Environment 568, 253-262 (2016)

14. C. Valente, A. Brekke, I.S. Modahl, Int. J. Life Cycle Assess. 23, 581-596 (2017)

15. A. Souza, M.D.B. Watanabe, O. Cavalett, C.M.L. Ugaya, A. Bonomi, Int. J. LCA 23, 617-628 (2016)

16. J. Ren, A. Manzardo, A. Mazzi, F. Zuliani, A. Scipioni, Int. J. LCA 20, 842-853 (2015)

17. S. Papong, N. Itsubo, P. Malakul, M. Shukuya, Sust, 7, 6, 1-30, (2015)

18. L. Petti, P.K. Sanchez Ramirez, M. Traverso, C.M.L., Ugaya C.M.L., Int. J. LCA 23, 569-580 (2016)

19. W. Chen, N.M. Holden, Int. J. LCA 22, 1459-1472 (2016)

20. J. Smith, D. Barling, Int. J. LCA 19, 944-949 (2014) 